\title{
Balancing Public and Private Interests in ICT Standardisation: The Case of AVS in China
}

\author{
Junbin $\mathrm{Su}^{1}$ and Vladislav V. Fomin ${ }^{2}$ \\ ${ }^{1}$ School of Journalism and Communication, Xiamen University, \\ Fujian 361005, China \\ ${ }^{2}$ Faculty of Informatics, Vytautas Magnus University, Lithuania \\ sujunbin@gmail.com, vvfomin@gmail.com
}

\begin{abstract}
This research inquires into how the public interest and private interests can be balanced by a new approach beyond the "Fair, Reasonable and Non Discriminatory" (FRAND) term and Royalty Free in the standardisation process. Using the case of Audio Video coding Standard (AVS) in China, we analyse the mechanisms for treating the Intellectual Property Rights associated with technical contributions of stakeholders and establishing a patent pool with low royalty. The lesson from the AVS case is that, in the Public Dominated Model of standardisation (PDM), public units can successfully contribute intellectual property but cannot easily match the role of private corporations in the standard's implementation. The public-private dilemma in standards development is more complex than that in terms of intellectual property rights.
\end{abstract}

Keywords: Standardisation, Public Interest, Private Interest, Audio Video Coding Standard (AVS), Public Dominated Model of Standardisation (PDM).

\section{Introduction}

A standard is usually thought of as a consensus on optimal solution for a specific technical problem $[1,2]$. The standardisation process, which involves evaluations of technical solutions and negotiations among stakeholders to achieve consensus on a technically optimal solution, is "by no means the execution of a linear techno-logic." "It is, rather, contingent on institutional factors, actor constellations, actors' interests and perceptions, technical knowledge, and what one might call the artifactual reference of specific coordination problem"[3]. There are bidirectional "translations" underlying the "top-down" management and "bottom-up" coordination processes $[4,5]$. On the one hand, the interests of stakeholders are "translated" into a technological contribution, which is expressed in technological language, then evaluated, negotiated and finally adopted into a technical solution. On the other hand, controversies and consensus on technical solutions are "translated" into interests (including the political and economic interests) of stakeholders $[6,7,8]$. At the end of this coordination process, a set of technical rules and sub-rules emerge as an outcome of interest negotiation among relevant actors, and are formulated as a technical standard [3]. When a standard which is adopted for use by society at large, has intellectual property rights 
associated with part of its technical specification, the complexity of the standardisation process acquires an additional dimension. Here, the status of the standard as a public good is juxtaposed by the temporary monopoly and associated monetary rewards on specific knowledge protected by intellectual property rights.

How can public interest be served under the existing techno-regulatory framework, especially in Information and Communication Technology (ICT) area? Egyedi has argued that there is "a regulatory asymmetry existing between Intellectual Property Right (IPR) interests and compatibility interests" and that "the primacy of IPR ownership and market competition" is anchored by current regulations while the societal significance of compatibility interests, that is public interest, is often neglected [9]. Such "asymmetry" of interests calls for novel theoretical and practical insights on whether the existing status quo can be redefined to better serve public interests. While "technical optimality" has traditionally been an expected prerequisite of standards, satisfying this condition in practice requires balanced representation of stakeholders' interests in the process, which in turn requires support by a proper institutional setup $[5,10]$.

This paper analyses the deficiency of the existing regulatory setup for handling the private and public interests in standardisation. Specifically, we show the limitations of the Fair, Reasonable and non-Discriminatory (FRAND) terms for handling intellectual property rights, and describe what may become a new approach to balance the private and public interests based on the case of the Chinese Audio Video coding Standard (AVS). Given the sheer volume and significance of ICT in today's information society, re-thinking the problem of better protecting public interest in ICT standardisation is timely and important.

\section{The Weak Position of Public Interest under the FRAND Terms}

Under the current institutional setup of the formal (committee-based) standardisation process, the holders of "essential" patents are expected to obey the FRAND licensing principle, while their actual interpretation of what FRAND means and how it can be implemented on a case-to-case basis is out of the control of a standard development organization (SDO). Such an organisational setup often contributes to a situation in which the patentee and the standard adopters would have different ideas on what FRAND means $[11,12]$.

The MPEG-family of standards presents an example, where the administration of the patent pool is carried out externally to the formal SDO body. MPEG LA is an agency which lies outside the formal SDOs, and is in charge of the MPEG-family standards and manages patent pools for patentees of MPEG2, H.264/AVC ${ }^{1}$, MPEG4 Visual and MPEG4 System. It seems that, by reducing the cost for patentees to license their patents together, MPEG LA could facilitate a broader adoption of the standards under the FRAND framework. Ex post, MPEG LA largely succeeded in doing that in the case of MPEG2 standard, and met users' reluctance to adopt MPEG4 standards because the royalty burden was perceived to be excessive by some. For

\footnotetext{
${ }^{1}$ H.264/AVC (Advanced Video Coding) is a CODEC standard developed by the ITU-T Video Coding Experts Group(VCEG) together with the ISO/IEC Moving Picture Experts Group (MPEG), which is technically identical to MPEG Part 10.
} 


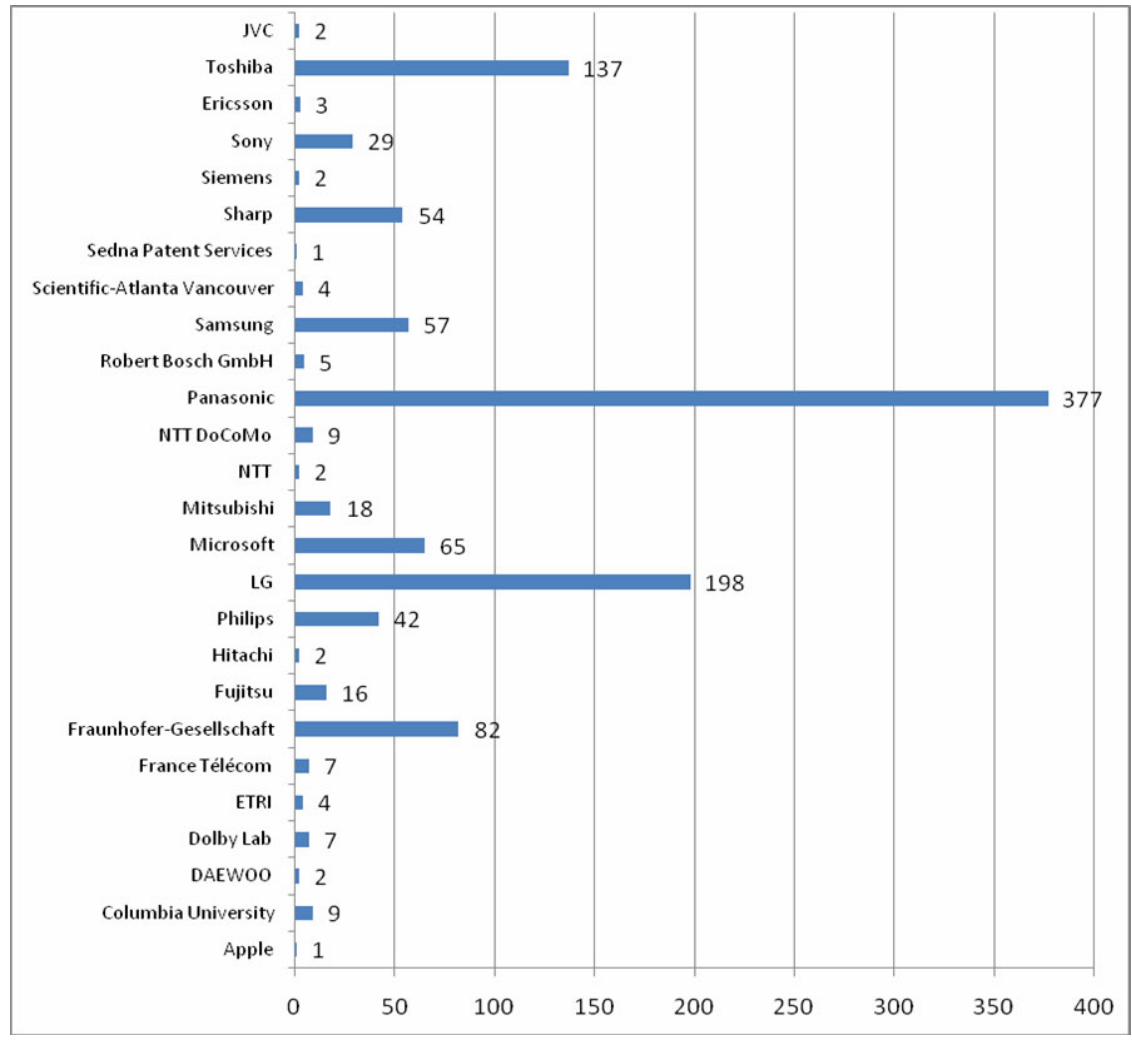

Fig. 1. Composition of Patent Pool of H.264/AVC ${ }^{2}$

example, the European Broadcast Union (EBU) claimed that it was disappointed by the MPEG LA's terms and conditions for the use of AVC [13]. The essential challenge underlying the MPEG LA case is that a "reasonable" requirement of FRAND is too vague and powerless to regulate the patent holders especially when patent licensing is dealt with outside the SDOs after standard-setting.

It is becoming more a rule than an exception that development of a public standard $^{3}$, such as H.264/AVC/MPEG4, is likely to involve contributions by private stakeholders which hold "essential" patents (as outlined in Fig.1). The patent pool of H.264/AVC/MPEG4 consists of 1135 patents, only 95 of which (less than 8.4\%) come from non-profit institutes that include, for example, Columbia University, the

2 The data in Fig.1 is sourced from the MPEG LA website, http://www.mpegla.com/, retrieved on May 6, 2010.

${ }^{3}$ We use the term "public" to denote the global and cross-industry significance of an ICT standard, and the fact that it is developed and maintained by international formal standard setting organisations whose mission are to develop standards, which can "facilitate universal access so that people everywhere can participate in, and benefit from, the emerging information society and global economy". See e.g. http://www.itu.int/net/about/mission.aspx/ 
Electronics and Telecommunications Research Institute, and the Fraunhofer Society for the advancement of applied research (Fraunhofer-Gesellschaft zur Foerderung der angewandten Forschung e.V.). The composition of H.264 /AVC patent pool indicates that technical contributions from private corporations dominate the technical coordination process which we refer to as the Private (interest) Dominated Model of standardisation. When most of essential patents or most of patentees in a public standard come from commercial corporations and could be licensed outside SDO under the FRAND, the public interest is under risk of being "kidnapped" through high royalty fees by the private interests of a few corporations. In the patent pool of H.264/AVC, 23 of all the 26 patentees are private corporations, by which AVC could be used as a tool either to pursue a monopoly high royalty fee or to limit the actions of possible new competitors.

The ambiguity of the FRAND principles have come to be a serious problem in ICT standardisation, as exemplified by MPEG standard licensing case, when private interests have diminished its success to be established as a standard that serves public interests. Especially when the standard is a multi-purpose and cross-industry "base" standard, such as MPEG standards, the obstacles caused by intellectual property right policies may have acted as true "reverse salients" that imposed a broad and deep retarding effect on technological innovation [14]. However, without assurance for the protection of, and rewards for, their intellectual property, there may be a lack of positive incentives to motivate private stakeholders to contribute to standards development. Such a juxtaposition of interests poses a question: how to deal with intellectual property rights more appropriately? How to protect the private interests of technical contributors while not sacrificing the public interests of users?

\section{Public Interest in AVS Standard Setting Process}

The Audio Video coding Standard (AVS) is an alternative standard set by the AVS Workgroup. It aims at solving the problem of an excessively high royalty fee caused by the domination of private interests in the H.264 or MPEG-family standards. To analyse the efforts of the AVS case is to shed light on a possible new approach to balancing public and private interests in ICT standardisation.

\subsection{The Mission of AVS}

The mission of AVS workgroup is to develop technical standards which serve public interests. Technically, the standard setting mechanisms of AVS (i.e., rules, procedures, and organisation of the standard setting process) are essentially the same as that of the ISO/IEC and the ITU which jointly developed H.264/AVC/MPEG 4: there, top-down management structure is combined with bottom-up decision making and technical contribution processes. What is different is the policy on intellectual property rights.

To avoid the vagueness of FRAND principle, AVS adopted a different approach to the two commonly used FRAND and "Royalty Free" approaches. In the case of AVS, there is a so-called "public technical standard with pre-defined competitive- price licensing of patent pool" [15]. The committee's decision on whether a stakeholder's 
technical contribution is acceptable is based on two factors. First, the technical contribution should be technically advanced and available. Second, essential patents should be licensed free or licensed in an AVS patent pool, which is formulated under the management of AVS workgroup during the standardisation process. The innovation of this AVS standardisation process is that licensing of essential patents is regulated ex ante, and not ex post, as in the case of FRAND policy based standard setting.

Another innovative aspect of AVS standard setting is that more than $20 \%$ of its members are public units which include universities and research institutes. These public units contribute most of the essential patents to the AVS standard. For example, six of the nine contributors to the AVS video part are public units. They include the Institute of Computing Technology of the China Academy of Science (CAS), Zhejiang University, Tsinghua University, Huazhong University of Science and Technology, Beijing University of Technology, and the Sun Yat-sen University. Public units contribute 37 of the total 42 technical contributions in AVS1-P2 and 35 of 52 contributions in AVS1-P7 (video for mobile application). The patent pool is managed by the AVS Patent Pool Administration Center which is a non-profit organisation [16].

\subsection{Public Interest Dominates AVS Standard Setting Process}

Standardisation has received considerable attention since the 1980s, when Farrell and Saloner compared the market, committee, and hybrid standardisation mechanisms. Formal negotiation through a committee can avoid some problems of market mechanism. Farrell and Saloner argued that a hybrid mechanism, and a market bandwagon plus committee negotiation could be more effective in coordinating the social benefits [17].

Schmidt and Werle criticised the economic models for concentrating on choices of actors on the basis of a presumed "payoff matrix" while completely ignoring the technical content of standards [3]. They argued that, besides economic interests, political and professional interests play crucial roles in standardisation: they formulated an alternative set of three modes of standardisation, namely governments, markets and committees, which produce respectively three categories of standards: mandatory, de facto or industry standards, and voluntary consensus standards [18, 19]. Because of technical "infrastructural characteristics", few standards are set by a pure market mechanism [20]. To balance the private interests and public interests, most standards are the outcomes of committee negotiation. But whether and how the committee mode differs within the different contexts is still unclear. How to set standards through a proper committee mode is an important problem to be solved.

The techno-political context established by China's National Plan - the Tenth FiveYear Plan, and the development of the hi-tech industry in particular, enables a better understanding of China's motivation to pledge to adopt 2,000 international standards a year for the first five years of the 21 st Century so as to reach the target of 80 per cent of key industrial standards that conform to international standards [21]. While key industrial standards are important in the context of export strategies, the strong emphasis on the development of endogenous hi-tech industries also needs the development of home-grown standards. The creation of a large number of endogenous standards requires a well-functioning standardisation infrastructure to support, maintain, and protect the intellectual property rights of the national standards, well-trained 
staff to undertake the research and development, and the integration of the national and international operation of the standards development.

With regard to standardisation infrastructure, the Standardization Administration of China (SAC) was set up at the top of the standards infrastructure hierarchy. The SAC has vice-ministerial status and is part of the Chinese General Administration of Quality Supervision Inspection and Quarantine (AQSIQ). The SAC was established to develop the Chinese standards agenda and to help bring domestic standards into alignment with international standards [22]. The AQSIQ emerged out of the reorganisation of China's standards system in 2001 which followed accession to the World Trade Organisation. The SAC now serves as China's "national body" to most international standards organisations including the International Standards Organization and the International Electrotechnical Commission which jointly develop MPEG-series standards. It oversees the administration of the national standards system [23].

With regard to handling intellectual property rights, the AVS Workgroup was established to operate an open, international development process, with an independent intellectual property rights policy. The goal of reducing licensing costs involves the AVS in developing a patent pool that tries to balance Chinese law and cultural values with global practices. The goal of a 1RMB (a Chinese yuan) license fee per unit of consumer-level encoders/decoders in China may not have been achieved, but the existence of AVS as a competitor to the H.264/MPEG4 standard, with lower license fees, may have encouraged the MPEGLA to lower royalty fees for its controlled standards: in the end, this meets the initial goals of the AVS project to re-define the balance between public and private interests in the audio-video codec standards domain.

Based on the case study of AVS standardisation, in our earlier work we formulated a model of committee standardisation, called the Public (interest) Dominated Model (PDM) [24]. The PDM has several distinctive characteristics as compared to the existing international regulatory standards development regime.

First, public institutions play a more visible role in the PDM. To avoid the heavy burden caused by adoption of foreign standards bearing intellectual property right royalties, government agencies in developing countries will encourage public research institutes and universities to play a dominant role in setting endogenous standards, thus complementing the weaknesses of domestic firms at least in an initial stage. As representatives of public interests, the purpose of public research institutes and universities involved in standard-setting is to enhance research capability and to train talent, not to pursuit economic interests. Therefore, it becomes possible under the PDM to form a patent pool with a low-fee license.

Second, under the PDM, intellectual property rights policies are made unambiguous ex ante. In the case of the AVS, participants must follow a strict intellectual property rights policy: according to it private patent holders could not claim patent royalty individually but have a binary choice of licensing it royalty-free or licensing it in the AVS patent pool. Standards set under the PDM are likely to have lower licensing costs, and thus contribute to wider adoption: the latter is especially important for innovation diffusion in developing countries.

Third, implementations of standards set under the PDM are likely to require more support from industries in an early stage. Because of the weaknesses of firms' 
participation in PDM standard-setting, most of the firms may ride the fence and wait for a bandwagon effect to emerge. Even though the intellectual property rights policies under the PDM may be helpful for the implementation of standards, the licensing cost is not the only factor that determines the behaviour of a firm in making an adoption decision. In the case of the AVS, there is an AVS Industry Alliance which is formed by 18 influential domestic firms to promote the application of AVS standards. The AVS Industry Alliance is expected to lead the creation of a bandwagon effect in the market.

The PDM can motivate public non-profit bodies effectively to contribute technical efforts to standard-setting. This is extremely important when the incentives of other participants are insufficient, as is often the case with formal standard-setting [5]. The PDM can also moderate, or even minimise, the risk of public standards being manipulated by private interests. By encouraging public bodies to play active roles in standardisation, the PDM can set up a patent pool which is timely and which protects both the public interests of a standard as a public good and the private interests of patent holders.

\section{Conclusion and Discussion}

Compared to developed countries, domestic firms and industries in countries that are catching-up possess less market and financial power and weaker research and development capabilities. Hence, their technical capability and willingness to contribute to international standardisation is considerably lower. The case of AVS shows that government agencies in developing countries can encourage public research institutes and universities to play an active and a visible role in setting standards and in supplying public expertise where there is a lack of private expertise. Such an approach can effectively diminish intellectual property rights' claims associated with the particular standard, as well as help to build the institutional and research and technical development expertise necessary to leverage a standards development infrastructure. As the representatives of public interests, the purpose of the public research institutes and universities that are involved in standard-setting is to enhance research capability and to train talents, not to pursuit economic interests.

The AVS case is far from being a success in terms of its implementation. While it is worthwhile to explore the Public Dominated Model of standardisation further, we learned from the AVS case that public units can successfully contribute intellectual property but they cannot easily match private corporations' roles in the standard's implementation. Usually, private corporations which could lead the standard's adoption would rather follow the bandwagon than actively lead it. On the other hand, public units were charged with the creation and contribution of intellectual property to the standard, and yet thus have no actual duty to implement standards in the market.

While a new patent pool approach proved a new promising solution to balancing public and private interest in standards, which carry the status of public good, it did not foster the implementation of AVS to the expected level. This makes us conclude that the public-private dilemma in standards development is more complex than that of intellectual property rights terms. Future research should take into account that a standard's users, setters, and society at large all have a different understanding of 
what represents an "optimal" balance of public and private interests in the standardisation process. The May 2010 announcement of Google's promoting of $\mathrm{WebM}^{4}-\mathrm{a}$ royalty-free and open source based video/audio CODEC format [26] - presents a good example of such a complex set-up, where the balancing of public-private interests spans across corporate and open source technology development and across royalty-free and intellectual property right-royalty based product offering. Thus, further research is needed to understand what the promising frameworks are for combining private and public interests in technology standards development to foster wider market implementation of standard-based technologies, products and services.

Acknowledgment. The authors thank the anonymous reviewers for their comments and advice on an early version of this paper. The research has received funding from the European Community's Seventh Framework Programme (FP7), under the grant agreement number SSH7-CT-2008-217457. The authors are also thankful to their Chinese and European colleagues from FP7's "China EU Information Technology Standard Research Partnership" project for their helpful suggestions on the AVS case study.

\section{References}

1. Sanders, T.R.B.: The Aims and Principles of Standardization. International Organization for Standardization, Geneva (1972)

2. Verman, L.C.: Standardization: A New Discipline. Ardon Books, Hamden, Conn. (1973)

3. Schmidt, S.K., Werle, R.: Coordinating Technology: Studies in the International Standardization of Telecommunications. MIT Press, Cambridge (1998)

4. Schmidt, S.K., Werle, R.: Technical Controversy in International Standardization, MPIFG Discussion Paper (935). Max Planck-Institut für Gesellschafsforschung, Köln (1993)

5. Fomin, V.V., Vries, H.J.D.: How balance is balanced enough? Case studies of stakeholders' (under-) representation in standardization process. In: Proceedings of the 6th Biennial Standardization and Innovation in Information Technology (SIIT) Conference, Tokyo, pp. 99-112 (2009)

6. Callon, M.: Some Elements of a Sociology of Translation: Domestication of the Scallops and Fishermen of St. Brieuc Bay. In: Law, J. (ed.) Power, Action and Belief, pp. 196-233. Routledge and Kegan Paul, London (1986)

7. Latour, B.: Science in Action: How to Follow Scientists and Engineers through Society. Harvard University Press, Cambridge (1987)

8. Su, J.: An Inquiry into the Coordination Mechanism of Technological Standardization in a STS Perspective. Ph.D. Dissertation. Tsinghua University, Beijing (2008)

9. Egyedi, T.M.: IPR Paralysis in Standardization: Is Regulatory Symmetry Desirable. IEEE Communications Magazine 4, 2-8 (2001)

10. International Telecommunication Union: ITU's history (December 12, 2009), http://www.itu.int/net/about/history.aspx

11. Stern, R.: Antitrust Division gives IEEE standard setters the okay to ask patentees how RAND they are. IEEE Micro, 106-109 (May-June 2007)

12. Cooke, W.: FRAND or Foe. Managing Intellectual Property 160, 31-33 (2006)

\footnotetext{
${ }^{4}$ WebM consists of the VP8 video codec and audio streams. It is an open, royalty-free standard and could be thought of as an alternative to H.264 in web-based application [25].
} 
13. European Broadcasting Union: EBU Technical Statement-D 96-2003: Joint H.264/MPEG4 AVC Patent License,

http: //www.subtel.cl/prontus_tvd/site/artic/.../

ebu_mpeg4_avc.pdf.

14. Hughes, T.P.: The evolution of large technological systems. In: Bijker, W.E., Hughes, T.P., Pinch, T.J. (eds.) The Social Construction of Technological Systems: New Directions in the Sociology and History of Technology, pp. 51-82. MIT Press, Cambridge (1993)

15. Huang, T., Gao, W., Reader, C.: A new approach for developing open standard with a more reasonable patent licensing policy (2006),

http: / /www.avs.org.cn/reference/

HuangLSSB-confirmed-final.pdf

16. Gao, W.: AVS: From an Idea to Practice (2008),

http://register.wise.astri.org/events/avsdb/presentations/AV

S_Talking_at_HK_forum_2008.pps

17. Farrell, J., Saloner, G.: Coordination through Committees and Markets. RAND Journal of Economics 19(2), 235-252 (1988)

18. David, P.A., Greenstein, S.: The Economics of Compatibility Standards: An Introduction to Recent Research. Economics of Innovation and New Technology 1, 3-41 (1990)

19. Blankart, C.B., Knieps, G.: State and Standards. Public Choice 77, 39-52 (1993)

20. Tassey, G.: Standardization in Technology-based Markets. Research Policy 29, 587-602 (2000)

21. Ure, J.: China Standards and IPR Chapter. Telecommunications Research Project, University of Honk Kong, http: / /www.trp.trpc. com.hk/papers / 2006 / china_ipr_stds_2006.pdf /

22. Suttmeier, R., Yao, X.: China's Post-WTO Technology Policy: Standards, Software and the Changing Nature of Techno-Nationalism. The National Bureau of Asian Research: Special Report, No. 7 (2004)

23. Suttmeier, R.P., Yao, X., Tan, A.Z.: Standards of Power? Technology, Institutions, and Politics in the Development of China's National Standards Strategy: The National Bureau of Asian Research, p.13 (2006)

24. Su, J., Fomin, V.V.: Public Dominated Standardization. Paper presented at the International Conference on Internet Technology and Applications, Wuhan, China, August 21-23 (2010)

25. WebM Project: What Is WebM? (May 25, 2010), http: / / www . webmproject.org/about/

26. Slivka, E.: Google Announces 'WebM' Open-Source Video Format, Plans for Android Television Integration (May 19, 2010),

http: / /www.macrumors.com/2010/05/19/

google-announces-webm-open-source-video-format-plans-forandroid-television-integration/ 